University of Montana

ScholarWorks at University of Montana

7-2006

\title{
Estimating Detection Probablities of River Birds Using Double Surveys
}

Robert J. Fletcher Jr.

Richard L. Hutto

University of Montana - Missoula, hutto@mso.umt.edu

Follow this and additional works at: https://scholarworks.umt.edu/biosci_pubs

Part of the Biology Commons

Let us know how access to this document benefits you.

\section{Recommended Citation}

Fletcher, Robert J. Jr. and Hutto, Richard L., "Estimating Detection Probablities of River Birds Using Double Surveys" (2006). Biological Sciences Faculty Publications. 271.

https://scholarworks.umt.edu/biosci_pubs/271

This Article is brought to you for free and open access by the Biological Sciences at ScholarWorks at University of Montana. It has been accepted for inclusion in Biological Sciences Faculty Publications by an authorized administrator of ScholarWorks at University of Montana. For more information, please contact

scholarworks@mso.umt.edu. 
The Auk 123(3):695-707, 2006

(C) The American Ornithologists' Union, 2006

Printed in USA.

\title{
ESTIMATING DETECTION PROBABLITIES OF RIVER BIRDS USING DOUBLE SURVEYS
}

\author{
Robert J. Fletcher, Jr. ${ }^{1}$ and Richard L. Hutto \\ Avian Science Center, Division of Biological Sciences, University of Montana, Missoula, Montana 59812, USA
}

\begin{abstract}
Aвstract. - We describe a method for surveying birds in river habitats that allows for rapid assessment across broad spatial scales and estimation of detection probabilities. Our river survey approach incorporates a double-survey technique, whereby observers in two canoes simultaneously survey birds along a river reach. Data are in the form of a two-sample mark-recapture history, and covariates suspected of influencing detection probabilities can be included in the modeling process and evaluated using information-theoretic approaches. We provide an example using the method along the Madison and upper Missouri rivers in Montana. Overall, detection probabilities for each observer ranged from 57\% to $89 \%$, and combined detection probabilities (the likelihood of at least one observer detecting an individual) were consistently high ( $88 \%$ across all species). Detection probabilities across species were positively correlated with body mass. Detection probabilities for some species were influenced by observer, river conditions, and whether species were in groups or alone; groups were more detectable, and individuals in slow-flowing and wide sections of river were more detectable. Boatbased double surveys are a viable method for estimating detection probabilities of birds in river habitats, and double surveys should be considered in other aquatic systems. Received 26 December 2004, accepted 17 September 2005.
\end{abstract}

Key words: density estimation, detection probability, double observer, LincolnPeterson, mark-recapture, monitoring, rivers.

\section{Estimaciones de Probabilidades de Detección de Aves de Río Utilizando Muestreos Dobles}

Resumen.-Describimos un método para muestrear aves en hábitats de río que permite realizar una determinación rápida a través de escalas espaciales amplias y que además permite estimar las probabilidades de detección. Nuestra propuesta de muestreo en ríos incorpora una técnica de muestreo doble, en la que observadores ubicados en dos canoas muestrean simultáneamente a las aves a lo largo de un río. Los datos son tomados como registros de dos muestras de marcado y recaptura, y las covariables que podrían influenciar la probabilidad de detección pueden ser incluidas en el modelo y evaluadas basándose en la teoría de la información. Proveemos un ejemplo utilizando este método a lo largo del río Madison y en las partes superiores del río Missouri en Montana. En general, las probabilidades de detección variaron entre un $57 \%$ y un $89 \%$ para cada observador, y las probabilidades de detección combinadas (probabilidad de que por lo menos un observador detecte un individuo) fueron constantemente altas (88\% para todas las especies). Las probabilidades de detección de cada especie se correlacionaron con el tamaño corporal de estas. Las probabilidades de detección para algunas especies estuvieron influenciadas por el observador, las condiciones del río y si las especies

${ }^{1}$ E-mail: robert.fletcher@mso.umt.edu 
se encontraban en grupos o solas. Los grupos y los individuos presentes en partes con flujo lento o en secciones anchas del río fueron detectados con mayor facilidad. Los muestreos dobles en bote son un método viable para estimar las probabilidades de detección de aves en hábitats de río y este tipo de conteos dobles deberían ser considerados también en otros sistemas acuáticos.

MONitoring POPUlation tREnds and habitat use of birds in river systems provides important data for evaluating water quality, human effects, and changes in river geomorphology (Stevens et al. 1997, Gergel et al. 2002, Sorace et al. 2002). However, it is often difficult to survey birds in river systems, because the habitats are linear and hard to get to, and because many species tend to move directionally upstream and downstream at relatively large scales (Stevens et al. 1997). Traditional land-based techniques, such as point counts and line transects (Hutto et al. 1986, Ralph et al. 1995, Buckland et al. 2001), are not effective, because (1) many species tend to use the landscape at relatively large scales and occur at relatively low densities; (2) some potential habitats are inaccessible from land (e.g., open water and islands); (3) many species vocalize rarely, which eliminates what is often the primary cue used in point counts; and (4) species are often difficult to see from shore. Other techniques, such as aerial surveys, can be expensive, and some species are difficult to identify from aircraft, which limits classification to family, genus, or guild.

Animal survey techniques generally need to account for detectability among species and habitats (Bayliss and Yeomans 1989, Buckland et al. 2001). Various methods exist for estimating detection probabilities, such as distance sampling (Buckland et al. 2001), removal methods (Farnsworth et al. 2002), double sampling or ratio sampling (Cochran 1977, Bart and Earnst 2002), double surveys (Magnusson et al. 1978, Graham and Bell 1989), and double-observer methods (Cook and Jacobson 1979, Nichols et al. 2000). Each of these methods includes different assumptions about factors influencing detectability of species and provides unique ways to deal with those factors. Some methods are specific to particular kinds of species (e.g., breeding songbirds that sing frequently; Farnsworth et al. 2002), whereas others are more general and can be applied in many situations and across a variety of taxa (e.g., Buckland et al. 2001). Experience with these approaches has made it apparent that different species have different detectabilities, and that various behavioral (e.g., group size; Graham and Bell 1989), ecological (e.g., habitat; Bayliss and Yeomans 1989), and methodological (e.g., observer bias; Nichols et al. 2000) factors can influence the detection of individuals.

Double surveys are a general technique whereby two observers independently sample the same area for species of interest. The two observers can use the same method or different methods to detect individuals (Magnusson et al. 1978, Caughley and Grice 1982, Lancia et al. 1994, Anthony et al. 1999). The double survey has also been termed an "independent double-observer" approach (Lancia et al. 1994). Here, we use the general term "double survey," because in some situations, the focus is different survey methods and not different observers (Magnusson et al. 1978, Anthony et al. 1999). Double surveys have had limited use in aerial surveys of largebodied birds (e.g., Bald Eagles [Haliaeetus leucocephalus]; Anthony et al. 1999), but the approach is flexible and can be used widely on many taxa in many habitats (Estes and Jameson 1988, Marsh and Sinclair 1989, Jachmann 2002). We used a double-survey approach to evaluate an untested survey technique for river birds along the Madison and Missouri rivers in Montana and extended the approach with model selection to examine covariates that can influence detection probabilities.

\section{Methods}

\section{A Double-survey Approach for Estimating Detection Probabilities}

When two observers perform standardized independent surveys of the same area, detection probabilities can be estimated by considering the approach as a closed-population LincolnPeterson model (Magnusson et al. 1978, Otis et al. 1978, Graham and Bell 1989). Two-sample individual capture histories are estimated for each species based on whether each observer 
detected an individual. Overall, three capture histories are possible for each individual: $x_{10}$ occurs when the first observer detects an individual but the second observer does not, $x_{01}$ occurs when the first observer does not detect an individual that the second observer does, and $x_{11}$ occurs when both observers detect the same individual.

Maximum-likelihood (ML) estimators of detection probabilities can be derived from the multinomial distribution, conditioning on $r$, the total number of distinct observations during the surveys (Graham and Bell 1989, Williams et al. 2002), where $r=x_{11}+x_{01}+x_{10}$. The ML estimators derived from a multinomial model for detection probabilities, $p$, of observer 1 and 2 are

$$
\hat{p}_{1}=\frac{x_{11}}{x_{11}+x_{01}} \text { and } \hat{p}_{2}=\frac{x_{11}}{x_{11}+x_{10}}
$$

where $p_{1}$ is the probability that observer 1 detects an individual, and $p_{2}$ the probability that observer 2 detects an individual. The ML estimator for the combined detection probability, $p_{t}$ (i.e., the probability that at least one surveyor detects an individual), is

$$
\hat{p}_{t}=\frac{r x_{11}}{\left(x_{11}+x_{10}\right)\left(x_{11}+x_{01}\right)}
$$

which can also be calculated as $\hat{p}_{t}=1-\left(1-\hat{p}_{1}\right)(1-$ $\left.\hat{p}_{2}\right)$. The variance of detection probabilities for each observer can be estimated by taking the negative inverse of the Hessian matrix (the second partial derivatives of the likelihood function, which we obtained numerically). The variance of combined detection probability can be approximated using the delta method as (Graham and Bell 1989)

$$
\operatorname{varr}\left(\hat{p}_{t}\right)=\frac{x_{01} x_{10}\left(x_{01}+x_{10}\right) \hat{p}_{t}}{\left(x_{01}+x_{11}\right)^{2}\left(x_{10}+x_{11}\right)^{2}}
$$

Total population size can be estimated as $\hat{N}=r / \hat{p}_{t}$. The variance of population size can be estimated using the delta method as (Nichols et al. 2000)

$$
\operatorname{var}(\hat{N})=\frac{r^{2} \operatorname{varr}\left(\hat{p}_{t}\right)}{\hat{p}_{t}^{4}}+\frac{r\left(1-\hat{p}_{t}\right)}{\hat{p}_{t}^{2}}
$$

Confidence intervals for population size can be approximated using the methods of Chao (1989). Density can be estimated as $\hat{D}=\hat{N} / A$, where $A$ is the area sampled, and the associated variance can be estimated as (Lancia et al. 1994, Farnsworth et al. 2002)

$$
\operatorname{vâr}(\hat{D})=(1 / A)^{2} \operatorname{van}(\hat{N})
$$

In many situations, detections incorporate groups of different sizes (Caughley and Grice 1982, Graham and Bell 1989, Marsh and Sinclair 1989, Jachman 2002). Group size can be incorporated into density estimation as $\hat{D}=\left(\hat{\bar{n}}_{d} \times r / \hat{p}_{t}\right) / A$, where $\hat{\bar{n}}_{d}$ is the average number of individuals per detection (Marsh and Sinclair 1989). The variance of $\hat{\bar{n}}_{d}$ can be incorporated into variance estimates of density using the delta method as

$$
\operatorname{vâr}(\hat{D})=\left(\begin{array}{l}
\frac{\hat{\bar{n}}_{d}^{2} r^{2} \operatorname{var}\left(\hat{p}_{t}\right)}{\hat{p}_{t}^{4}}+ \\
\frac{\hat{\bar{n}}_{d}^{2} r\left(1-\hat{p}_{t}\right)}{\hat{p}_{t}^{4}}+ \\
\frac{r^{2} \operatorname{var}\left(\hat{\bar{n}}_{d}\right)}{\hat{p}_{t}^{2}}
\end{array}\right) \frac{1}{A^{2}}
$$

where

$$
\operatorname{vâr}\left(\hat{\bar{n}}_{d}\right)=\frac{\sum_{i=1}^{r}\left(n_{i}-\hat{\bar{n}}_{d}\right)^{2}}{r(r-1)}
$$

(cf. Buckland et al. 2001:72).

Assumptions of this approach can be addressed by noting standard closed-model mark-recapture assumptions (Otis et al. 1978, Seber 1982):

(1) Closure. - Because double surveys are conducted simultaneously, the closure assumption is justified. Animals moving in and out of the study area ("open") will be similarly identifiable to both observers.

(2) No lost "tags." - Because double surveys are conducted simultaneously, this assumption is met.

(3) Equal capture probability. - All animals of each species are assumed to have equal detection probabilities for each observer. Although heterogeneous detection probabilities could occur among individuals, conventional trapresponse effects in mark-recapture models are not pertinent because of simultaneous sampling. Magnusson et al. (1978) suggested that violating this assumption does not tend to bias estimates derived from double surveys. Yet with knowledge of potential factors influencing 
detection probabilities, sampling can be stratified and tests for heterogeneous detection probabilities conducted (Skalski et al. 1983, Rivest et al. 1995).

(4) Correct marking. - The correct identification of unique detections of individuals is an important assumption of the double-survey technique. Previous accounts of this approach have noted that correct marking would be difficult for moving animals (Pollock and Kendall 1987); modern mapping techniques using geographic information systems (GIS) and global positioning systems (GPS) can help address this issue.

(5) Independent trapping sessions (observers).Observers must survey areas independently of each other. A variety of measures can be taken to maximize the likelihood of independence between observers. If independence does not occur between observers, estimated detection probabilities will likely be biased higher than true detection probabilities (Nichols et al. 2000). Although this is a concern, these detection probabilities are still closer to true estimates than uncorrected count indices (Nichols et al. 2000).

(6) Catchable population. - Detection probabilities using the double-survey approach account only for individuals in populations that are observable (see also Moore et al. 2004).

It is clear that only assumptions (3) through (6) are truly relevant to double-surveys. One final assumption of double surveys is:

(7) Observers survey the same areas. - When double surveys occur independently, it is critical that each observer is surveying the same area. This requires specific delineation of studyarea boundaries.

We extend previous approaches that used chi-square goodness-of-fit and likelihood-ratio tests for estimating heterogeneous capture probabilities (Skalski et al. 1983, Rivest et al. 1995) to an information-theoretic framework (Burnham and Anderson 2002). Likelihood functions can be developed to incorporate $a$ priori covariates believed to influence detection probability, and models can be compared using Akaike's Information Criterion adjusted for sample size (AIC ; Burnham and Anderson 2002). Huggins $(1989,1991)$ developed a linearlogistic multinomial model, conditioned on $r$, which allows covariates to be included in the model. Using Huggins's models to analyze double surveys can be accomplished in MARK
(White and Burnham 1999) by setting $p_{2}=c$, where $c$ is generally considered the probability of recapture (Moore et al. 2004). An advantage of information-theoretic approaches in determining heterogeneity of capture probabilities lies in the ability to simultaneously compare non-nested models with different factors potentially influencing detection probabilities.

\section{An Application to River Birds}

Study area.-To test the double-survey approach for river birds, we surveyed birds along the Madison and Upper Missouri rivers in Montana (Fig. 1), as part of a larger project on bird communities that use the river system. Both rivers are relatively shallow and surrounded by cottonwood (Populus spp.) and willow (Salix spp.) riparian habitats, grasslands, shrubsteppe, and agriculture. In the sections we surveyed, the Madison River is generally narrower (Madison: $\bar{x}=55.9 \mathrm{~m}$; Missouri: $\bar{x}=112.4 \mathrm{~m}$ ), faster flowing (Madison: $\bar{x}=138.6 \mathrm{~m} \mathrm{~min}^{-1}$; Missouri: $\bar{x}=$ $120.3 \mathrm{~m} \mathrm{~min}^{-1}$ ), more braided, and less geomorphically constrained than the Missouri River.

We divided the entire stretch of river into twenty-three 18 - to $40-\mathrm{km}$ segments based on available public-access locations on the river. From these 23 segments, we randomly selected 14 for surveys (stratified geographically), and double surveys were conducted on a random sample of 6 of the 14 segments surveyed. Here, we include only data from double surveys. We used the double-survey approach to survey birds along $46.0 \mathrm{~km}$ of the Madison River and $109.3 \mathrm{~km}$ of the Missouri River (Fig. 1). Overall, each segment averaged $25.9 \mathrm{~km}$ (range: $19.2-32.7 \mathrm{~km}$ ).

River canoe surveys. - We surveyed river bird communities along the Madison and Upper Missouri rivers by canoe from 18 May to 10 July 2004 (Fig. 1; cf. Stevens et al. 1997). We chose a canoe-based technique over other techniques for two reasons. First, canoes provide access to all portions of this river system, unlike other types of boats that either have restricted access (motor boats) or are inefficient in slow-moving portions of the river (rafts). Second, canoe surveys allow for distinguishing all species, unlike aerial surveys that are of limited use for smallbodied birds and often require pooling species into groups.

Double surveys consisted of two simultaneous surveys, where observers in two canoes 


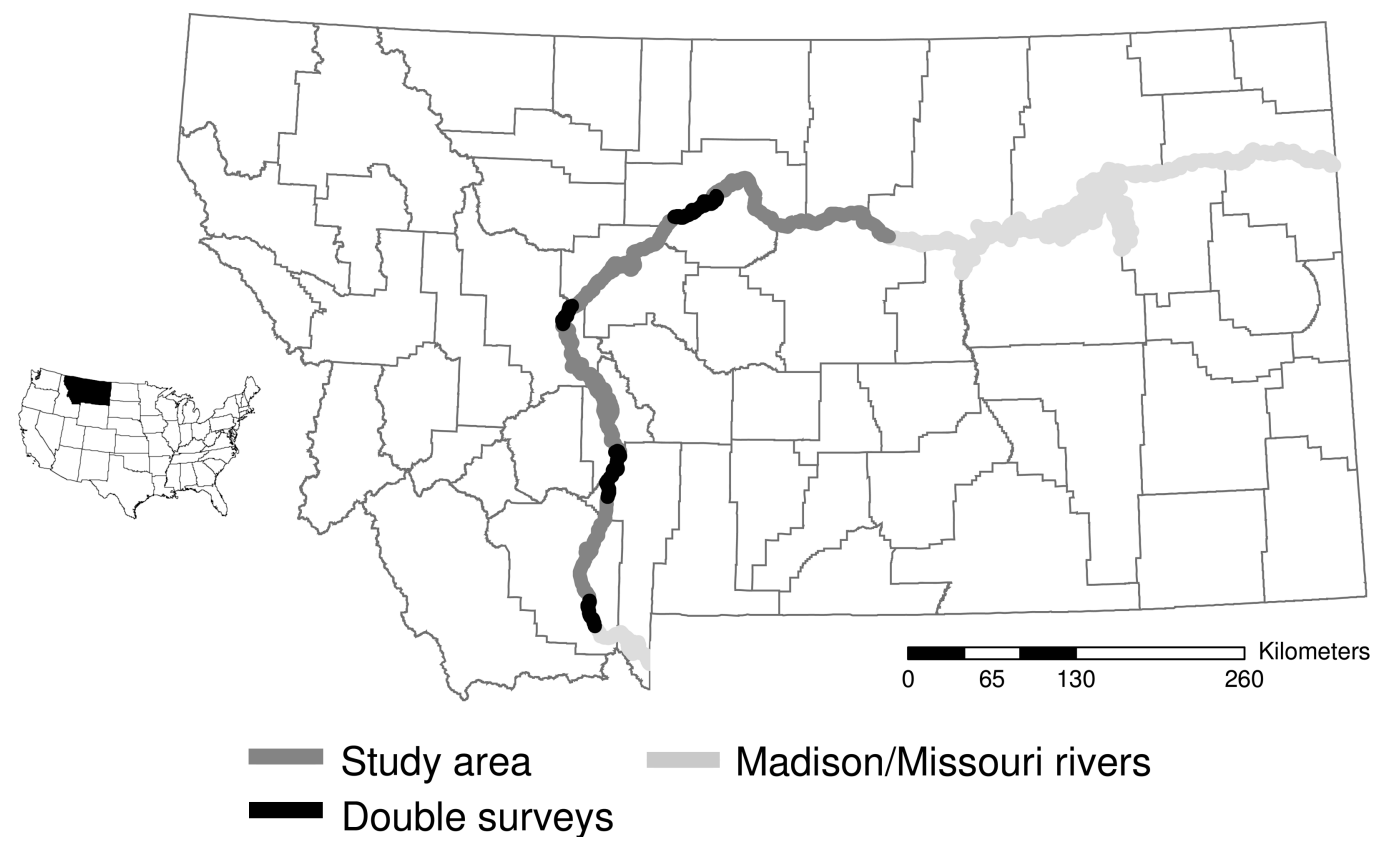

Fig. 1. Double-survey locations for estimating detection probabilities of birds along the Madison and Upper Missouri rivers, Montana, 2004. Note that in two situations, double-survey segments adjacent to each other were selected, so that it appears as if only four stretches were surveyed.

(two observers in each canoe) independently surveyed areas. We attempted to maximize independence of surveys by maintaining $>20 \mathrm{~m}$ between canoes at all times. We also instructed observers not to focus on other observers while locating individuals during surveys. From each canoe, two observers recorded all nonpasserine birds seen using or flying above the river system. Flyovers were recorded within $100 \mathrm{~m}$ of the water's edge, whereas other birds were recorded within the high-water mark of the river. Primary observers were in the bows of the canoes; their main objective was to survey and record all birds. Secondary observers were in the sterns; their main task was to steer and navigate the boat, and their secondary objective was to survey birds, notifying the primary observer of individuals detected. For each detection, we recorded the species, sex, number of individuals (group size), and location along the river (in water, on island, on left or right bank of river, or in flight). All detections were recorded using a GPS unit. Using this technique, river segments of the lengths we traversed could be surveyed in approximately 4-6 h. Birds were surveyed between 0500 and 1130 hours (MST). Because observers within a canoe were considered a survey group, and to be consistent with the double-survey approach outlined above, we refer to observers in canoe 1 as "observer 1, ," and observers in canoe 2 as "observer 2."

We considered observers to have made the same detection if GPS locations were within $50 \mathrm{~m}$, if time of observation was the same, and if the described location was consistent between observers (e.g., Spotted Sandpiper on the left bank of river; see Table 1 for scientific names). We used $50 \mathrm{~m}$ as a cut-off because the maximum float rate was $202.9 \mathrm{~m} \mathrm{~min}^{-1}$ (average $=131 \mathrm{~m} \mathrm{~min}^{-1}$; see below) and GPS error was approximately $\pm 10 \mathrm{~m}$. We did not include flyovers in any analysis, for two reasons: (1) GPS locations between observers for individual flyovers probably vary substantially because of bird movement in flight and (2) whether individuals flying over the river are using it for breeding or foraging activities is often equivocal. For some detections $(n=24$; 8 species), it appeared that observers were detecting the same individuals (judging from 


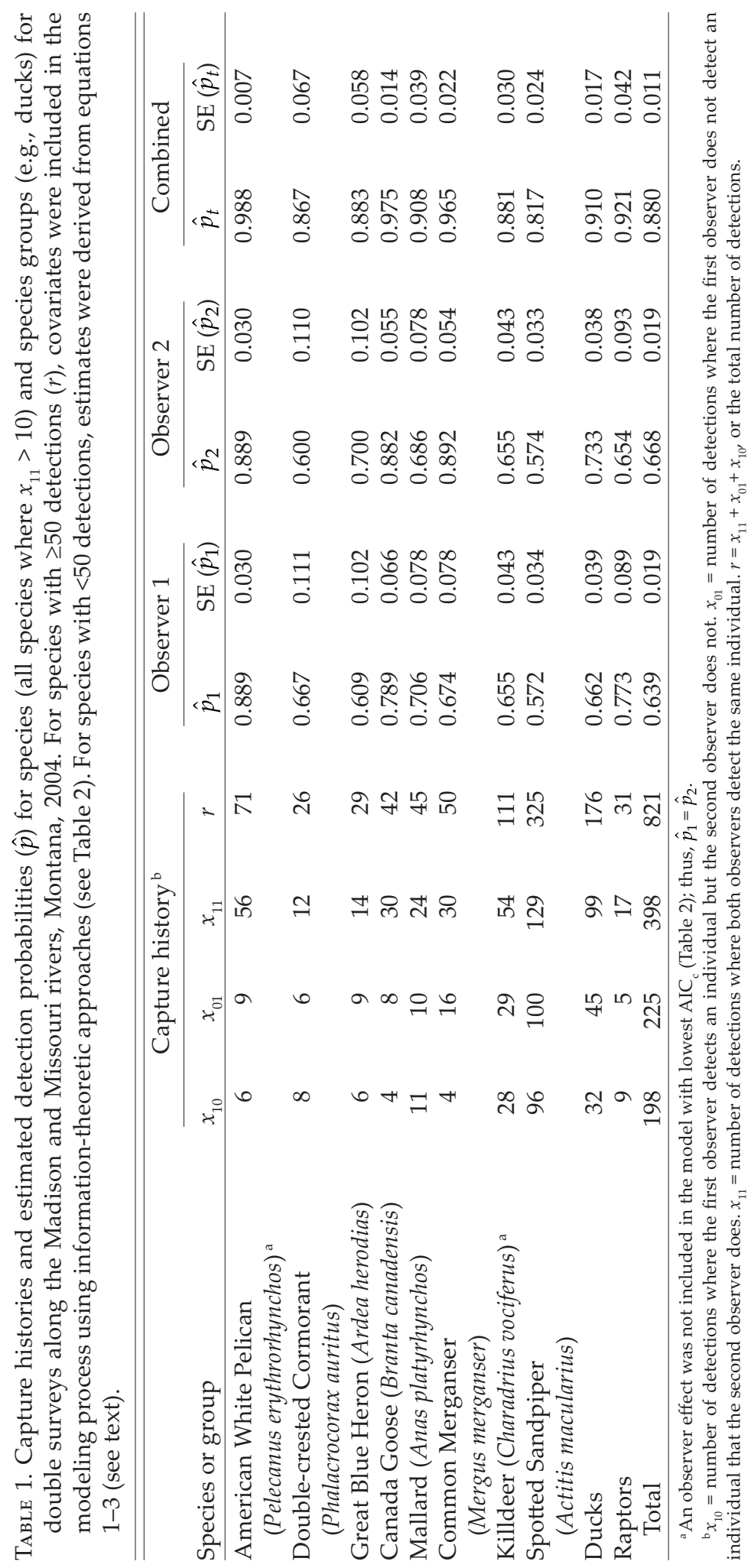


species rarity, consistent descriptions of locations between observers, and time detected), and yet GPS locations were $>50 \mathrm{~m}$ apart. We did not include these in the analysis, either as mark-no recapture or as mark-recapture, to minimize either positive or negative bias in detection probability estimates.

Statistical analysis. - We estimated baseline detection probabilities for all species with $\geq 10 \quad x_{11}$ capture histories (using equations 1-3), but also considered covariates believed to influence detection probabilities for more common species using the Huggins model and an information-theoretic approach (see below). Seber (1982) and Rivest et al. (1995) suggested that when $x_{11}>6$, the bias of the correction factor $(1 / \hat{p})$ is negligible. In addition, we pooled some species a priori into multispecies groups (ducks, raptors) to estimate combined detection probabilities for relatively rare species (sensu Nichols et al. 2000). Pooling requires that species within groups have similar detection probabilities, which was likely for the groups we considered (Table 1).

We were interested in three covariates that could influence detection probability: group size, river width, and flow rate. Pilot surveys conducted in 2003 gave us reason to believe that detection probability should be lower in wide than in narrow sections of rivers, and in fast-flowing than in slow-flowing sections (see Caughley [1974] for similar arguments in aerial surveys). In addition, it is widely known that group size can influence detectability during double surveys (Graham and Bell 1989, Jachmann 2002; but see Bayliss and Yeomans 1989). Using GPS locations and GIS, we estimated river width $(\mathrm{m})$ for each detection. At $2.5-\mathrm{km}$ intervals, we estimated survey speed $\left(\mathrm{m} \mathrm{min}^{-1}\right)$, extrapolated from time taken at GPS locations. We used a $2.5-\mathrm{km}$ interval because the maximum distance between locations for which we had time information was $2.46 \mathrm{~km}$. We initially categorized detections into solitary individuals, small groups (2-5 individuals), and large groups ( $>5$ individuals). However, we recorded large groups for only two species: American White Pelican and Canada Goose. Thus, we pooled detections into solitary or group detections for all species but also estimated detection probabilities according to group size for American White Pelicans and Canada Geese.
We used an information-theoretic approach to find the most parsimonious model for estimating detection probabilities for species and multispecies groups with $\geq 50$ detections (Table $1)$. For each species, we compared candidate models that incorporated different covariates believed to influence detection probabilities, using AIC and AIC model weights (Burnham and Anderson 2002). We compared a series of reduced models that included observer $(o)$, group size ( $g$; in a group or alone), and river condition $(r$; which included both river width and river flow rate, $f+w)$, to a global model: $p[o \times(g+r)]$. We chose that global model because we reasoned that different observers could be differentially influenced by covariates, but that covariates were generally independent (additive) in their influence on detection probability. Reduced models included all combinations of the global model, because we considered each factor to be potentially important independently of other factors. All analyses were performed in MARK (White and Burnham 1999).

On the basis of estimated detection probabilities from the model with the lowest $\mathrm{AIC}_{c^{\prime}}$ we estimated bird density for the Madison and Missouri rivers using data for each observer and from both observers combined. Because detections were often in groups, we incorporated group size as described above into density estimates. To estimate density for each observer, we only included data from that observer in the estimation process. For example, density can be estimated from data collected by observer 1 as $\hat{D}_{1}=\left[\hat{\bar{n}}_{d 1} \times\left(x_{11}+x_{10}\right) / \hat{p}_{1}\right] / A$, where $\hat{\bar{n}}_{d 1}$ is the average number of individuals per detection for observer 1. Comparing estimates between single observers and both observers combined illuminates the potential for extrapolating detection probabilities to larger areas surveyed by one of the observers involved in the double survey.

\section{Results}

Overall, we accumulated 821 capture histories across 33 species. Detection probabilities (from equations 1-3) were highly variable among species, ranging from $57 \%$ to $89 \%$ for each observer (Table 1). Combined detection probabilities were consistently high, however, ranging from $82 \%$ to 99\% (Table 1). Small-bodied shorebirds (Killdeer and Spotted Sandpiper) tended to have the 
lowest detection probabilities, whereas American White Pelican had the highest estimated detection probabilities. Using body masses reported in Dunning (1993), there were positive correlations between body mass and detection probability for observer $1(r=0.68, P=0.063)$, observer $2(r=0.70$, $P=0.053)$, and combined detection probabilities $(r=0.75, P=0.030)$ (Fig. 2).

For one of the five species or multispecies groups modeled to determine the potential influence of covariates on detection probabilities, a constant detection probability adequately explained the data (Killdeer; Table 2). For the other species modeled, there was some support for including group size, river condition, and observer in modeling detection probabilities (Table 2). For these species, detection probability generally increased in groups, decreased with flow rate and, surprisingly, increased with river width (Fig. 3). For American White Pelican and Canada Goose, detection probabilities were similar for small (pelican: $\hat{p}_{t}=0.989 \pm 0.011$; goose: $\hat{p}_{t}=0.988 \pm 0.017$ ) and large (pelican: $\hat{p}_{t}=$ $0.991 \pm 0.009$; goose: $\hat{p}_{t}=0.961 \pm 0.027$ ) groups.

We estimated density for each species and multispecies group for the Madison and Missouri rivers using the most parsimonious model to explain detection probability (from Table 2). Estimated densities from observer 1 were

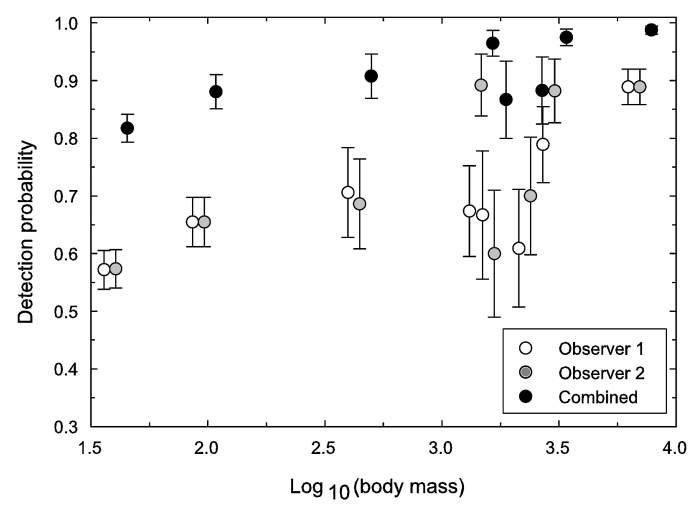

FIG. 2. Estimated detection probabilities as a function of bird body mass for each observer and the combined detection probability based on double surveys along the Madison and Upper Missouri rivers, Montana, 2004. Body mass values among observer categories were offset slightly $\left( \pm 0.05 \log _{10}\right.$ [body mass]) to reduce overlap and increase figure clarity. Body mass values were taken from Dunning (1993). slightly higher than estimates from combined detection probabilities, whereas estimates from observer 2 were typically lower (Table 3$)$. Yet for every species considered, confidence intervals of density estimates overlapped for each observer and both observers combined (Table 3 ).

\section{Discussion}

Detection probabilities and density estimation.Detection probabilities among species varied in predictable ways, primarily with variations in body size. Overall, small-bodied species tended to have lower detection probabilities than larger-bodied species (see also Jachmann 2002), but body size was not the only factor contributing to differences among species. For example, Common Merganser had a higher detection probability than the larger Great Blue Heron, likely because Great Blue Herons tend to perch in dense vegetation along the river banks not moving or vocalizing, whereas Common Mergansers more frequently perch on boulders in the river. Thus, both behavioral and habitat-use characteristics associated with different species may help explain remaining variability in detection among species.

Within species, groups tended to have higher detection probabilities than solitary individuals, which is consistent with other investigations (e.g., Graham and Bell 1989, Jachmann 2002; but see Bayliss and Yeomans 1989). We expected that detection probabilities would decrease with river width and flow rate, but in species where river condition was included in models, detection probability increased with river width, counter to our expectations. That relationship likely occurred because the narrowest areas in our system were along the Madison River, where the river was more braided, streamside vegetation was relatively dense, and river flow rate was faster than on the Missouri River, causing birds to be less conspicuous than along the Missouri River.

Confidence intervals of density estimates from each observer overlapped with estimates using both observers, which suggests that detection probabilities based on double surveys from a random subsample of data could be applied to larger areas surveyed by one observer, in a manner similar to double-sampling approaches (Bart and Earnst 2002). However, there were subtle differences between observers, where observer 1 tended to estimate slightly larger 

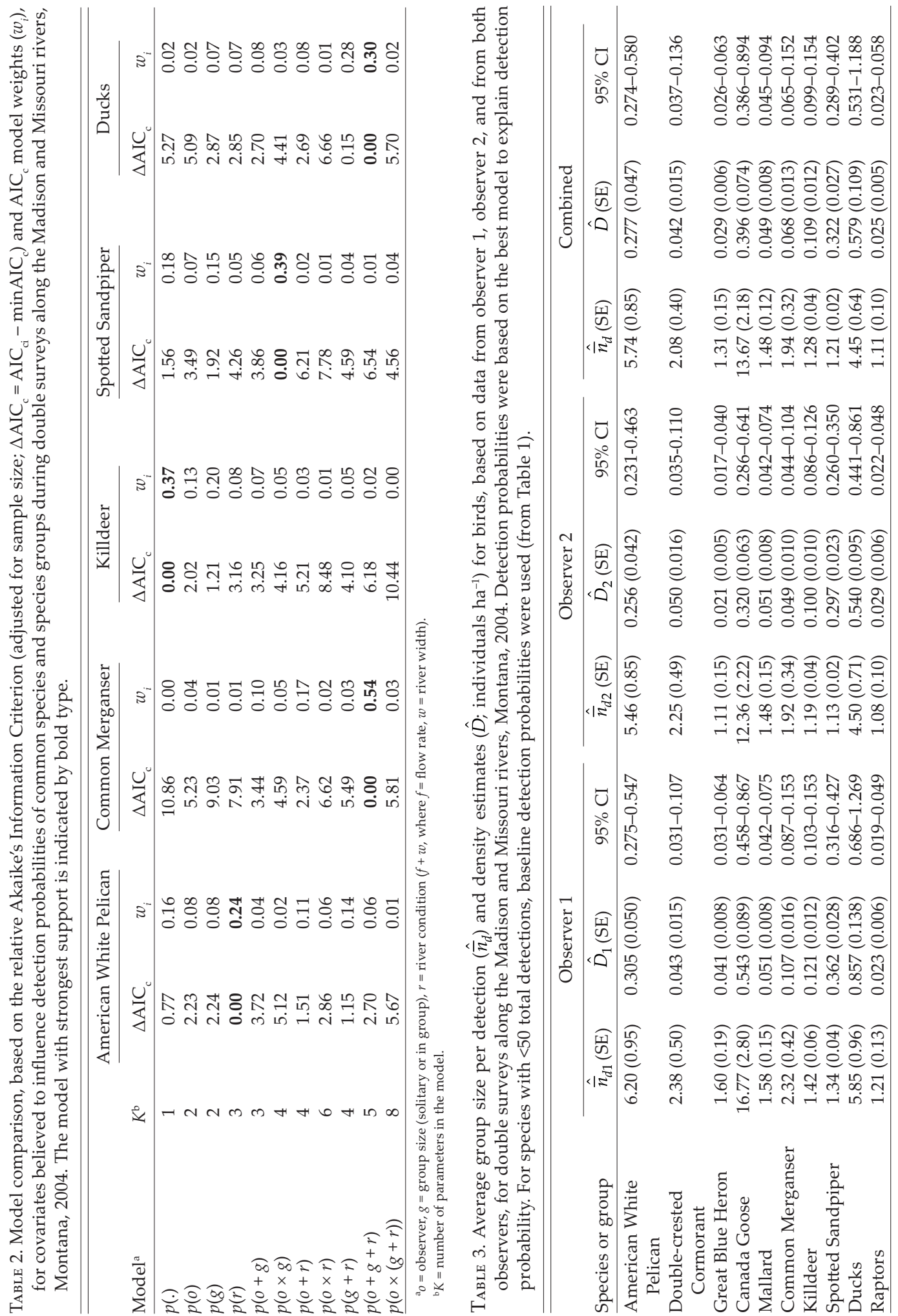
A) American White Pelican

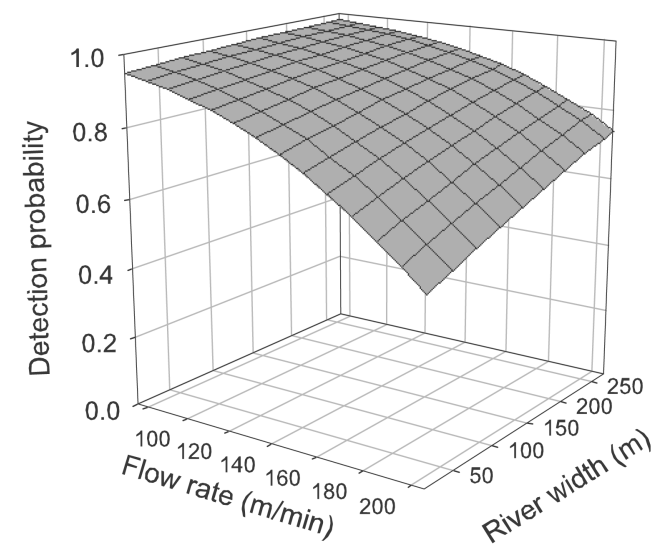

C) Common Merganser

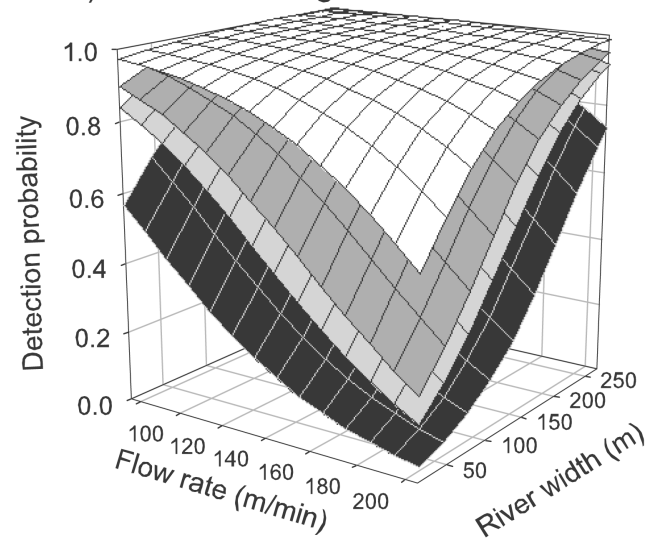

B) Spotted Sandpiper

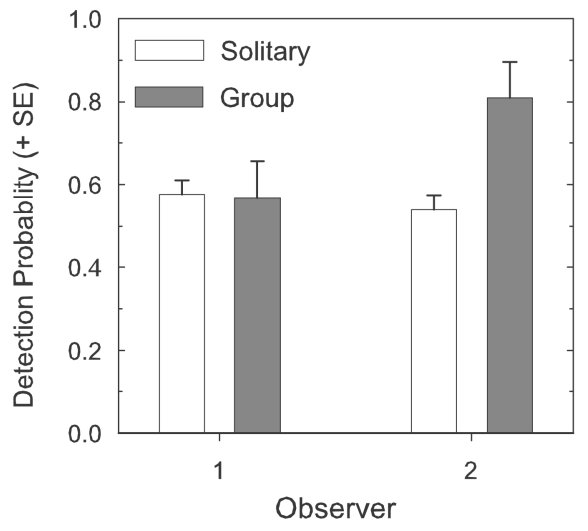

D) All ducks

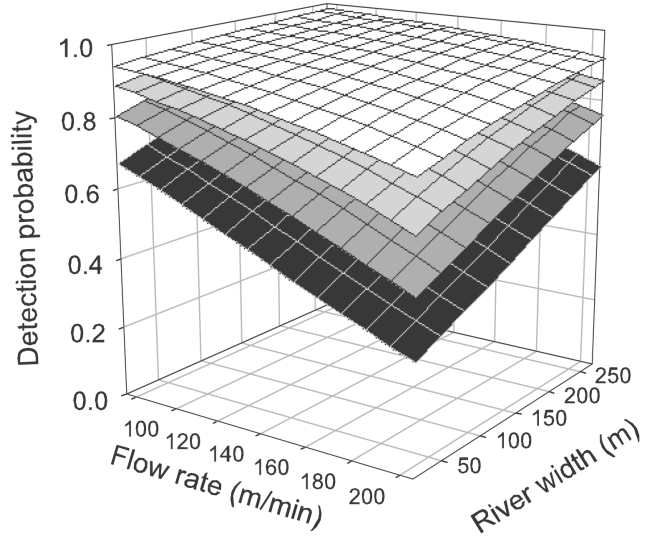

Fig. 3. Detection probabilities from models with the lowest Akaike Information Criterion (adjusted for sample size; AIC $_{\mathrm{c}}$ ) that considered observer, group size, and river condition (river flow rate and river width) based on double surveys along the Madison and Upper Missouri rivers, Montana, 2004. Only species and species groups where covariates were included in the best model are included (see Table 2). On panels C-D, black indicates observer 1 and detections of solitary individuals, dark gray indicates observer 1 and group detections, light gray indicates observer 2 and detections of solitary individuals, and white indicates observer 2 and group detections.

group sizes than observer 2 (Table 3), which resulted in point estimates typically being higher for observer 1. Although using double surveys on a subsample of data might be a cost-effective approach for estimating population size or density, we recommend that double surveys be conducted on a large portion of the study area, if not the entire area, which would increase precision and reduce bias in estimates of group size and detection probabilities. The usefulness of this technique ultimately rests on the ability to produce unbiased estimates of population size or density. Testing these methods against a population of known density would provide important data for evaluating potential bias and determining whether detection probabilities can be applied to larger areas surveyed by one observer.

Double surveys as an alternative to other survey techniques. - Double surveys have some advantages over existing approaches for estimating detection probabilities. Because surveys are 
simultaneous, estimated detectabilities reflect conditions encountered during the survey (Rivest et al. 1995), as opposed to more general estimates derived across all surveys (Buckland et al. 2001). Most assumptions of the approach are easily met, and some modeling suggests that the technique is relatively robust to violations of certain assumptions (Magnusson et al. 1978, Caughley and Grice 1982). Furthermore, statistical techniques for double surveys rely on a strong foundation of mark-recapture approaches (Otis et al. 1978, Seber 1982) and can be implemented with existing software (e.g., MARK).

Our initial reason for choosing a doublesurvey approach for estimating detection probabilities was the difficulty of implementing other approaches in a river canoe survey. For example, estimating distances to individuals would have been difficult for primary observers because of the relatively fast movement of canoes and other recording problems, such as GPS marking of locations. Double sampling was not used because it would require different intensive sampling methods for different species in the diverse river community. Double-observer methods (Cook and Jacobson 1977, Nichols et al. 2000) could be used in our river survey technique by adding a third observer situated in the center of a single canoe. We initially considered that approach, but decided on a double-survey approach for two reasons: (1) the likelihood of independence between observers should be greater for double surveys, judging simply from the greater physical distance between observers; and (2) adding a third observer in our canoe surveys could make navigation more difficult because of increased weight in the canoe. Double-observer techniques also assume that observers have similar detection probabilities when acting as primary or secondary observers, but our approach does not need to make that assumption. Graham and Bell (1989) compared the two methods and found that the Cook-Jacobson estimator (double-observer approach in Nichols et al. 2000) was less efficient than the Lincoln-Peterson double-survey estimator. The Cook-Jacobson estimator is less efficient because it does not include information on all detections by secondary observers but instead includes only information on detections by secondary observers that primary observers missed (Graham and Bell 1989).
There are a few disadvantages of double surveys compared with other techniques. First, it is difficult to know whether the assumption of independence between observers is truly met in double surveys (see also Nichols et al. 2000). Second, it is difficult to know whether animals are correctly tagged during surveys, because even if both observers observe an individual of the same species in the same general location at the same time, the observers may be detecting different individuals. That would cause a bias in detection probabilities, which would be estimated higher than the true detection probabilities for a species (Magnusson et al. 1978, Caughley and Grice 1982). Incorrect tagging probably increases with population density (Caughley and Grice 1982, Pollock and Kendall 1987, Graham and Bell 1989), which would reduce the effectiveness of double surveys in high-density situations. In our system, birds were relatively rare, with the most commonly detected species, the Spotted Sandpiper, observed only at $\sim 0.2$ detections per $100 \mathrm{~m}$ for both observers combined. GPS locations of detections allow biologists to use different radii for tagging individuals, which can help in understanding the potential bias involved in incorrect tagging of individuals. We initially used a 100-m radius for tagging individuals, which resulted in slightly higher detection probabilities of most species. Yet incorrect tagging is also an issue for double-observer techniques (Nichols et al. 2000) and similar issues occur in single-observer sampling (e.g., failing to record an individual because an observer believes that it is the same individual as another nearby).

Finally, it is important to note that the primary detection problems that double surveys account for are observer- and visibility-bias, not distance-related detection concerns. Because we focused on relatively large-bodied species in an open-water river system, we were less concerned about distance-related issues and more concerned about observer-related biases. When distance sampling is difficult or assumptions are not likely met, or when other non-distance-related detection issues are the primary concern, a double-survey approach can be a suitable alternative to other techniques for estimating detection probabilities. Furthermore, when distance estimation is possible during double surveys, detection distances can also be included as a covariate in modeling, thereby 
including multiple sources of detection bias in the estimation process.

Conclusions. - A double-survey approach for surveying river birds provided a rigorous approach for estimating detection probabilities in boat-based surveys. Although some species had high detection probabilities, thus reducing the information gained with double surveys, others had lower detection probabilities that were influenced by group size, river condition, and observer. The probability that at least one observer would detect an individual was consistently high, which suggests that double surveys greatly increase the likelihood of detecting individuals. We recommend considering this approach in river bird surveys, particularly for small-bodied species that have low detection probabilities, and double surveys can potentially be incorporated into other survey techniques, such as point counts (e.g., Moore et al. 2004). Double surveys could also be used on a random subsample of surveys to estimate detection probabilities that can then be used for entire sets of single-observer surveys. Detection probabilities estimated from double surveys can then be included in monitoring population trends, effects of land and water management, estimation of population size, and other important conservation issues regarding river bird populations.

\section{AcKnowledgments}

We thank PPL Montana for providing financial and logistical support for this project. R. Hazlewood and J. Jordonais provided additional support. Thanks to J. Harris, S. Robertson, J. Csoka, J. Young, M. Rohmeier, and G. Huber for valuable field assistance. D. Tessin gave thoughtful comments on statistical analysis. A. Cilimburg, D. Haukos, J. Nichols, and two anonymous reviewers made helpful comments on previous drafts of this manuscript.

\section{Literature Cited}

Anthony, R. G., M. G. Garrett, and F. B. Isaacs. 1999. Double-survey estimates of Bald Eagle populations in Oregon. Journal of Wildlife Management 63:794-802.

Bart, J., AND S. EARnst. 2002. Double sampling to estimate density and population trends in birds. Auk 119:36-45.
Bayliss, P., and K. M. Yeomans. 1989. Correcting bias in aerial survey population estimates of feral livestock in northern Australia using the double-count technique. Journal of Applied Ecology 26:925-933.

Buckland, S. T., D. R. Anderson, K. P. Burnham, J. L. LAake, D. L. Borchers, and L. Thomas. 2001. Introduction to Distance Sampling: Estimating Abundance of Biological Populations. Oxford University Press, Oxford.

Burnham, K. P., and D. R. Anderson. 2002. Model Selection and Multimodel Inference: A Practical Information-theoretic Approach, 2nd ed. Springer-Verlag, New York.

Caughley, G. 1974. Bias in aerial survey. Journal of Wildlife Management 38:921-933.

Caughley, G., and D. Grice. 1982. A correction factor for counting emus from the air, and its application to counts in western Australia. Australian Wildlife Research 9: 253-259.

ChAO, A. 1989. Estimating population size for sparse data in capture-recapture experiments. Biometrics 45:427-438.

Cochran, W. G. 1977. Sampling Techniques, 3rd ed. John Wiley and Sons, New York.

Cook, R. D., AND J. O. Jacobson. 1979. A design for estimating visibility bias in aerial surveys. Biometrics 35:735-742.

Dunning, J. B., JR., ED. 1993. CRC Handbook of Avian Body Masses. CRC Press, Boca Raton, Florida.

Estes, J. A., And R. J. Jameson. 1988. A doublesurvey estimate for sighting probability of sea otters in California. Journal of Wildlife Management 52:70-76.

Farnsworth, G. L., K. H. Pollock, J. D. Nichols, T. R. Simons, J. E. Hines, and J. R. Sauer. 2002. A removal model for estimating detection probabilities from point-count surveys. Auk 119:414-425.

Gergel, S. E., M. G. Turner, J. R. Miller, J. M. Melack, And E. H. Stanley. 2002. Landscape indicators of human impacts to riverine systems. Aquatic Sciences 64:118-128.

Graham, A., and R. Bell. 1989. Investigating observer bias in aerial survey by simultaneous double-counts. Journal of Wildlife Management 53:1009-1016.

Huggins, R. M. 1989. On the statistical analysis of capture experiments. Biometrika 76: 133-140. 
Huggins, R. M. 1991. Some practical aspects of a conditional likelihood approach to capture experiments. Biometrics 47:725-732.

Hutto, R. L., S. M. Pletschet, and P. Hendricks. 1986. A fixed-radius point count method for nonbreeding and breeding season use. Auk 103:593-602.

JACHMANN, H. 2002. Comparison of aerial counts with ground counts for large African herbivores. Journal of Applied Ecology 39: 841-852.

Lancia, R. A., J. D. Nichols, and K. H. Pollock. 1994. Estimating the number of animals in wildlife populations. Pages 215-253 in Research and Management Techniques for Wildlife and Habitats (T. A. Bookhout, Ed.). Wildlife Society, Bethesda, Maryland.

Magnusson, W. E., G. J. Caughley, and G. C. GrIGg. 1978. A double-survey estimate of population size from incomplete counts. Journal of Wildlife Management 42:174-176.

Marsh, H., ANd D. F. Sinclair. 1989. Correcting for visbility bias in strip transect aerial surveys of aquatic fauna. Journal of Wildlife Management 53:1017-1024.

Moore, J. E., D. M. Scheiman, and R. K. SwiHARt. 2004. Field comparison of removal and modified double-observer modeling for estimating detectability and abundance of birds. Auk 121:865-876.

Nichols, J. D., J. E. Hines, J. R. Sauer, F. W. Falon, J. E. Fallon, and P. J. Heglund. 2000. A double-observer approach for estimating detection probability and abundance from point counts. Auk 117:393-408.

Otis, D. L., K. P. Burnham, G. C. White, And D. R. Anderson. 1978. Statistical inference from capture data on closed animal populations. Wildlife Monographs, no. 62.

Pollock, K. H., ANd W. L. Kendall. 1987. Visibility bias in aerial surveys: A review of estimation procedures. Journal of Wildlife Management 51:501-510.

Ralph, C. J., J. R. SAuer, and S. Droge, Eds. 1995. Monitoring bird populations by point counts. U.S. Department of Agriculture, Forest Service, General Technical Report PSW-GTR-149.

Rivest, L.-P., F. Potvin, H. Crépeau, and G. DAIgle. 1995. Statistical methods for aerial surveys using the double-count technique to correct visibility bias. Biometrics 51:461-470.

Seber, G. A. F. 1982. The Estimation of Animal Abundance and Related Parameters, 2nd ed. Charles Griffin, New York.

Skalski, J. R., D. S. Robson, And M. A. Simmons. 1983. Comparative census procedures using single mark-recapture methods. Ecology 64: 752-760.

Sorace, A., P. Formichetti, A. Boano, P. Andreani, C. Gramegna, and L. Mancini. 2002. The presence of a river bird, the Dipper, in relation to water quality and biotic indices in central Italy. Environmental Pollution 118:89-96.

Stevens, L. E., K. A. Buck, B. T. Brown, And N. C. KLINE. 1997. Dam and geomorphological influences on Colorado River waterbird distribution, Grand Canyon, Arizona, USA. Regulated Rivers: Research and Management 13:151-169.

White, G. C., and K. P. Burnham. 1999. Program MARK: Survival estimation from populations of marked animals. Bird Study 46 (Supplement):S120-S138.

Williams, B. K., J. D. Nichols, and M. J. Conroy. 2002. Analysis and Management of Animal Populations. Academic Press, San Diego, California.

Associate Editor: D. A. Haukos 